\title{
Neuroeconomics: two camps gradually converging: what can economics gain from it?
}

\author{
Jack Vromen
}

Published online: 4 June 2011

(C) The Author(s) 2011. This article is published with open access at Springerlink.com

\begin{abstract}
Neuroeconomics started off as a hybrid project. Two camps, behavioral economics in the scanner (BES) and Glimcher's economics of neural activity (ENA), could be clearly distinguished. The camps disagreed not only about substantive issues but also about what neuroeconomics ultimately aims to accomplish. Recent developments suggest that the gap between the two camps is closing, however. There is a growing consensus, it seems, about the brain areas in which the final stages of individual decision-making occur and about relevant features of brain activity in these areas. BES and Glimcher's ENA also seem to converge on the view that the neuroeconomics' ultimate aim is to contribute to the construction of a new utility theory with stronger predictive power than standard expected utility theory. While the potential importance of an improved utility theory for economic theory cannot be denied, however, it remains to be seen whether an improved utility theory is something economic theory needs most badly or most urgently. Especially if economic theory is not ultimately interested in individual decisions, but in how aggregate behavior responds to incentives, attention should not be limited to what happens inside the skulls of individuals. What happens outside the individuals' skulls, in the environments of individuals and in their interactions patterns, should also receive due attention.
\end{abstract}

Keywords Neuroeconomics - Decision-making - Behavioral economics in the scanner $\cdot$ Economics of neural activity

JEL Classification B41 $\cdot$ D03 $\cdot$ D87

\footnotetext{
J. Vromen $(\bowtie)$

EIPE, Faculty of Philosophy, Erasmus University Rotterdam, Rotterdam 3000 DR, The Netherlands e-mail: vromen@fwb.eur.nl
} 


\section{Introduction}

Neuroeconomics is sometimes presented as an interdisciplinary endeavor that brings together economics and neuroscience. ${ }^{1}$ This raises at least as many questions as it answers. How are economics and neuroscience brought together in neuroeconomics? As two indispensable, equally important sources of knowledge and tools for addressing particular issues? Or are economics and neuroscience supposed to mutually enrich and inform each other in neuroeconomics? If so, what does such a form of cross-fertilization look like? Or is neuroeconomics a one-street affair in which neuroscience enriches and informs economics? Or, finally, does neuroeconomics amount to a reduction of economics to neuroscience? Is the guiding idea that in the end a fully mature neuroscience will tell us everything we want to know about decisionmaking so that there is no need any more for a separate economic decision theory?

In this paper, I tackle these questions not by surmising what neuroeconomics could be in principle, but by having a close look at how neuroeconomics is actually practiced. I start with a discussion of how neuroeconomics emerged as a new field with two very different camps. I will dwell on the many differences between themsome substantive, having to do with different views on how the brain functions, and others more directly related to the very understanding of the new field of neuroeconomics and of what it ultimately aims to accomplish. I will illustrate one major substantive disagreement between the two camps with a discussion of neuroimaging studies of intertemporal choice. Subsequently, I argue that the two camps seem to be converging now on many different counts. I conclude the paper with a discussion of what economics, given its traditional concerns and subject matter, can expect to gain from neuroeconomics.

\section{Neuroeconomics launched: two camps}

Until recently, the widespread belief among economists was that neuroeconomics amounts to an attempt to take recourse to the insights, findings and tools of neuroscience so as to inform and enrich economics. Though not completely wrong, this view is one-sided. As Vromen (2007) and Ross (2008) argue, rather than assuming that neuroeconomics is a unitary movement, neuroeconomics comprises two rather different camps. One camp, aptly called ehavioral economics in the scanner (BES) by Ross (2008), fits the rough-and-ready characterization given above. BES holds that insights and findings from neuroscience show the need to revise economic theory. The other camp, which I would like to call economics of neural activity (ENA), seems to be altogether different. Instead of using insights and findings from neuroscience to guide revisions in economic theory, ENA uses standard economic theory to study neural activity. Let us have a closer look at the two camps and how they differ.

\footnotetext{
${ }^{1}$ Sometimes psychology is added as the third discipline involved in neuroeconomics (cf. Glimcher 2010).
} 


\subsection{BES: using brain data to support behavioral models}

Camerer and Loewenstein (2004), Camerer et al. (2005) was the first manifesto of BES. In their manifesto, Camerer et al. argue that there is a lot that economists can learn from neuroscience. Prior to the advent of neuroscience, economists had no other choice than to "black box" what is going on inside the human mind and brain during decision-making. With the emergence of new neuro-imaging technology (such as PET and fMRI scans), Camerer et al. argue, it has become possible for neuroscientists to open the black box of the brain to see how decisions are actually made. Camerer et al. argue that the findings of the brain scans done so far clearly suggest that automatic rather than consciously controlled behavior is the default mode of operation in human behavior. In contrast to consciously controlled behavior, automatic behavior typically occurs without awareness, is accompanied by a subjective feeling of effortlessness, is reflexive (that is, not evoked deliberately) and is not introspectively accessible. ${ }^{2}$ Due to the latter feature, the causes behind most of our behavior elude us. Attempts to access these causes can be made and are often made, but are most likely to lead to spurious sense-making. Attempts can also be made to override automatic, affect-driven behavior cognitively. But such attempts happen less frequently than we wish to think and are often not successful (like countering our longing for calorie-rich food in a diet). Camerer et al. conclude that since on the narrow technical understanding of "rational behavior" in standard economic theory only consciously controlled cognitive-driven behavior is rational, current neuroscience suggests that most of human behavior is not covered by standard economic theory.

Camerer et al. (2005) also stress that neuroscience strongly suggests that often emotion (or affect) rather than deliberation (or "cool cognition") is primary in driving behavior. An early neuroeconomic case in point is Sanfey et al. (2003). Sanfey et al. used fMRI to study the brains of subjects in ultimatum bargaining games. What they found is that three brain regions were activated in the subjects: the dorsolateral prefrontal cortex (DLPFC), the anterior cingulate (ACC) and the insula cortex. Based on what was previously known about these brain regions, Sanfey et al. hypothesized that the brain struggles (in the ACC) to resolve the conflict between seizing the planned reward value (in the DLPFC) and the negative emotion of disgust associated with being presented with a low offer (in the insula). What prevents subjects from behaving as predicted by game theory, Sanfey et al. argue, is this latter negative emotion of disgust. Note that Sanfey et al.'s study exhibits one of BES's distinguishing features, the postulation of the existence of multiple distinct valuation systems in the brain. Behavior is assumed to be the outcome of the interaction between multiple brain systems.

Another neuroeconomic study that attracted a lot of attention is De Quervain et al. (2004). De Quervain et al. study the neural basis of altruistic punishment. People engage in altruistic punishment if they punish norm violations at considerable personal cost without the prospect of the cost being recouped in the future.

\footnotetext{
${ }^{2}$ See also Kahneman (2003) similar distinction between System 1 and System 2 type cognitive processes and the by now vast literature on dual process (or dual system) theories (cf. Evans 2010).
} 
De Quervain et al. find that people with a greater willingness to incur personal cost in punishing social norm violators also had a greater activation in their dorsal striatum. De Quervain et al. argue that this finding supports the "social preference" hypothesis that people derive psychic satisfaction from punishing norm violators. They argue that this hypothesis implies that reward-related brain regions should be activated. They rely on earlier (single-neuron) studies in neuroscience that are argued to reliably indicate that the striatum is a key part in reward-related neural circuits (De Quervain et al. 2004, 1254). De Quervain et al. thus treat their findings about the neural basis as evidence supporting their behavioral (social preference) model.

Studies such as Sanfey et al. (2003) and De Quervain et al. (2004) exhibit two features that are characteristic of BES. One is that they rely on earlier studies in neuroscience in linking the execution of specific modes of mental behavior with observations of increased activation in particular brain areas. Sanfey et al. rely on earlier studies that showed that the occurrence of negative emotions such as disgust was accompanied by increased activation of the insula cortex. They consider their observation of increased activation of the insula cortex to be evidence that subjects confronted with (what they take to be) unfair offers feel disgust. De Quervain et al. similarly rely on earlier studies that showed that goal-directed behavior was accompanied by increased activation of the dorsal striatum. They consider their observation of increased activation of the dorsal striatum to be evidence that subjects confronted with norm violation seek "sweet revenge". Poldrack (2006) argues convincingly that this involves committing the "reverse inference fallacy". From the fact that some brain region was activated when individuals engaged in some particular mental activity or task, it cannot be reversely inferred that the particular mental activity is executed whenever it is observed that the brain region is activated. The simple reason for this is that the same brain region might be activated also when other sorts of mental activity are executed. And in fact, Poldrack suggests that the latter possibility actually obtains. What we know about the brain thus far suggests that there is not the kind of "strong selectivity" in our brain that would be needed to warrant making inverse inferences.

The second feature exhibited by Sanfey et al. (2003) and De Quervain et al. (2004) is that they regard their own findings as direct empirical support for behavioral models. The titles of both studies indicate that attempts are made to identify the neural basis of decision-making. But that does not seem to be their ultimate goal. Their ultimate goal seems to be to muster evidence that supports behavioral models. The authors see their results as evidence that utility functions should make room for social preferences such as fairness and strong reciprocity. In short, BES treats findings obtained with brain scans as direct evidence suitable for adjudicating economic models in the battle between standard economic theory and behavioral models. Gul and Pesendorfer (2008) object that brain data cannot play this role. Their main argument is that standard economic theory does not make specific predictions about brain states and brain processes. Economic theory makes specific predictions only about choices. Therefore, only choice data can (dis)confirm economic theory. Brain data cannot play the adjudicating role that proponents of BES assign to it. In response to Gul and Pesendorfer (2008), Camerer (2008) argues that Gul and Pesendorfer's case for mindless economics rests on two dubious arguments. The first is a "fundamentalist definition" of economics that denies the possible relevance of 
all non-choice data (not only neural data, but also psychological data) for economic theory by definition. The second argument is that standard economic theory is flexible enough to explain behavioral anomalies. Camerer argues that although it might be possible to explain anomalies with the conventional language of preferences, beliefs and constraints, at some point introducing constructs from other fields (such as psychology and neuroscience) is less contrived and clumsy.

In sum, BES argues that the lesson to be learned from neuroscience is that economic theory is ripe for changes and revisions. In the short run, there might only be incremental changes in economic theorizing resulting from taking neuroscience's findings and insights seriously. The basic building blocks of standard economic theory, preferences, constrained maximization, and equilibrium (Camerer et al. 2005, 55), might survive, albeit in a slightly revised and extended form. Social preference models are a case in point. But in due time, Camerer et al. argue, more radical departures from standard economic theory will become necessary. There will have to be models starting from a very different basis than preferences, constrained maximization, and equilibrium. In a nutshell, nothing short of a revolution in economic theorizing is expected to be the eventual result of findings and insights from neuroscience finding their way into economics.

\subsection{ENA: using standard economic theory to guide the study of neural activity}

Glimcher's (2003) version of Neuroeconomics is very different in several respects. First, Glimcher is not an economist addressing an audience of economists, but a neurobiologist addressing fellow neuroscientists. Glimcher pleads for a revolution in neuroscience, not in economic theory. Glimcher argues that neuroscience has been in the grip of Sherrington's reflexological paradigm for ages. The challenge was to find the minimal set of neurobiological components that could account for an elementary behavior such as a knee-jerk reflex. This reflexological approach worked pretty well for simple sorts of behavior, Glimcher argues, but failed to account for more complex behavior involving mutual interactions between components and feedback from the environment. Evidence is accumulating that neural activity is much more responsive to changes in rewards and in probabilities of rewards than the reflexological model suggests. Glimcher argues that standard economic theory (basically expected utility theory and game theory) provides a good starting point to analyze neural activity in brain areas that are implicated in decision-making. Thus, rather than using insights from neuroscience to improve standard economic theory, as BES aims to do, Glimcher's ENA uses standard economic theory to improve neuroscientific theory.

Glimcher (2003) was partly based on Platt and Glimcher (1999) and Dorris and Glimcher (2004). In Platt and Glimcher (1999) a so-called cued saccade experiment is conducted with thirsty rhesus monkeys. The monkeys were presented with sequential displays of dots of light with different colors on a screen in front of them. They could earn squirts of orange juice by looking at the "right" spot on the screen. Platt and Glimcher found that variations in rewards and probabilities of rewards were not only tracked by the monkeys' eye movements, but also by action potential and firing rates of corresponding groups of neurons in area LIP (the lateral intraparietal area of the posterior parietal cortex, which was antecedently known to be crucially implicated in 
such tasks). Expected utility theory thus turns out to predict not only observable choice behavior of monkeys pretty well, Platt and Glimcher conclude, but also neural activity in area LIP. Dorris and Glimcher (2004) confirms that standard economic theory (this time game theory) quite accurately predicts not only the overt behavior of monkeys, but also the neural behavior in their area LIP. This bolsters Glimcher's confidence that expected utilities are computed, in a quite literal way, in the brain:

Neoclassical theory has always made the famous as if argument: it is as if expected utility was computed by the brain. Modern neuroscience suggests an alternative, and more literal, interpretation. The available data suggest that the neural architecture actually does compute a desirability for each available course of action. This is a real physical computation, accomplished by neurons, that derives and encodes a real variable. The process of choice that operates on this variable then seems to be quite simple: it is the process of executing the action encoded as having the greatest desirability (Glimcher et al. 2005, 8).

Camerer et al. (2005) and Camerer (2007) likewise conceive of the surprising findings obtained by Glimcher and colleagues as evidence supporting standard economic theory. They hasten to add, however, that the countervailing evidence disconfirming standard economic theory is massive and overwhelming: on balance, the odds are clearly against standard economic theory and in favor of attempts at revising economic theory that are in line with behavioral economics' main tenets.

It is telling that in their introduction to the Handbook of Neuroeconomics (Glimcher et al. 2008), the editors do not hide the internal division prevailing in neuroeconomics. Glimcher, Camerer, Poldrack, and Fehr acknowledge “... an interesting split that persists in neuroeconomics today" (ibid., 7) and observe that "in a real sense, then, these economists turned to neurobiology for exactly the opposite reason that the neurobiologists had turned to economics" (ibid., 9). Neurobiologists like Glimcher had turned to standard economic theory to find a suitable theory to study neural behavior, whereas economists such as Camerer and Fehr turned to neurobiology to undergird the need for overturning standard economic theory.

In short, it seems that the discipline that the one camp seeks to revolutionize is considered to be in a perfectly good shape by the other. In particular, whereas behavioral economists believe that we can learn from current neurosciences that standard economic theory is in bad need of substantive revisions, Glimcher seems to believe that neuroscience should start applying standard economic theory to improve their understanding of neural activity. Whereas the latter could be interpreted as one more feat of economics imperialism, the application of standard economic theory to phenomena that are traditionally understood to be outside the scope of economic theory, behavioral economists believe standard economic theory does not even do a good job in addressing economic theory's traditional home ground.

\section{A case in point: intertemporal choice}

Camerer et al. (2005) argue that neuroscience provides ample reason to believe that consciously controlled decision-making and automatic behavior are two distinct 
modes of behavior that are implemented in spatially distinct systems in the brain. The idea, central to BES, that there are two neutrally separable systems in the brain underlying two different sorts of mental processes has been a long-standing target for Glimcher. Glimcher et al. $(2005,216)$ argue that this idea is based on outdated neuroscience. Contemporary neuroscience is moving in exactly the opposite direction, they argue. Instead of positing that there are two distinct decision-making systems in the brain, contemporary neuroscience now is venturing the hypothesis that there is one unitary decision-making process (Parker and Newsome 1998; Schall and Thompson 1999; Glimcher 2003). This disagreement between the two camps is particularly salient in the camps' different views on intertemporal choice.

Above, we saw that Camerer et al. (2005) argue that a (and perhaps the) takehome message from neuroscience for economics is that there are two distinct systems working in the human brain that jointly produce behavior. Brocas and Carrillo $(2008,2010)$ elevate the view that there are two distinct neural systems in the human brain to one of neuroeconomics' centerpieces. Dual-process theories (or dual systems theories; cf. Evans 2010, Kahneman 2003) posit the existence of two processes in the human mind, an evolutionarily ancient one and an evolutionarily more recent one. The evolutionarily ancient process is supposed to be intuitive, fast, parallel, and automatic in the sense that it feels effortless to the agent in question. The evolutionarily more recent process, by contrast, is supposed to involve conscious reasoning and is furthermore supposed to be slow, serial, and cognitively controlled (it feels effortful to the agent). Camerer et al. (2005) argue that in the interaction of the two systems the evolutionarily ancient one often dominates.

Dual-process theory plays an important role in explaining peculiarities of intertemporal choice. Standard economic theory assumes that people discount future outcomes exponentially. But experimental findings strongly suggest that people value immediate rewards (as compared with future rewards) even more strongly than standard economic theory assumes. This hyperbolic discounting of future rewards might explain why people sometimes exhibit preference reversals (also called dynamically inconsistent choices), as in the case when someone plagued by toothaches makes an appointment with his dentist a few weeks later but does not show up because he gets cold feet one day before the appointment. Several economists have tried to model this as a game between two selves: an impulsive impatient one and a patient one taking into account long-term consequences and being able to implement self-control (cf. O'Donoghue and Rabin 1999; Gul and Pesendorfer 2001; Fudenberg and Levine 2006).

Laibson (1997) constructs a quasi-hyperbolic model to account for dynamically inconsistent choices. In this quasi-hyperbolic model, it is assumed that there are two distinct discounting systems working in tandem: a $\beta$-system, which is assumed to be activated only when there are immediate rewards, and a $\delta$-system, which is assumed to be activated invariably by rewards (whether they are immediate or delayed). McClure et al. (2004) hypothesize that there are two distinct systems in the brain that (as neural correlates) implement the $\beta$-system and the $\delta$-system: the mesolimbic dopamine system, which in earlier studies was shown to be implicated in impulsive behavior, implements the impatient system (or "self") and the fronto-parietal system, which in earlier studies was shown to be implicated in cognitively 
controlled behavior, implements self-control. McClure et al. (2004) use fMRI scans to show that these distinct brain regions are indeed differentially activated when rewards are either immediate or delayed. They argue that these findings support dual systems theories about cognitive function.

Contrary to McClure et al. (2004, 2007), Kable and Glimcher (2007) and Glimcher et al. (2007) do not find differential activation in the medial prefrontal cortex, the ventral striatum, and the posterior cingulate cortex when agents are engaged with intertemporal choice. Thus, Glimcher et al. (2007) contradict McClure et al. (2004, 2007)'s main conclusion that there is neural evidence for the existence of two separate valuation systems in the brain. Interestingly, Kable and Glimcher do not deny that there is behavioral and neural evidence for hyperbolic (rather than exponential) discounting. This might come as a surprise, for earlier work by Glimcher in ENA suggested that Glimcher holds that standard economic theory does a good job in predicting both behavioral and brain data. But now Glimcher et al. concede that a behavioral hyperbolic discounting model fits behavioral and brain data better than a standard exponential discounting model.

Glimcher et al. do deny, however, that the sort of hyperbolic discounting observed lead to dynamically inconsistent choices. What they observed is that agents consistently prefer gains "as soon as possible", regardless of whether "as soon as possible" is a matter of seconds or months. For our present purposes, the most important finding in Glimcher et al. (2007) is, however, that the activity in any of the three brain regions mentioned above (the medial prefrontal cortex, the ventral striatum, and the posterior cingulate cortex) is found to be tightly correlated to the behavioral data. In short, they do not find any neural evidence for positing the existence of two separate, distinct valuation systems in the brain. Glimcher et al. do not seem to deny that there can be internal mental strife, between keeping to a wellconsidered plan for action (as a diet) and momentary temptations (as consuming that bar of chocolate), for example. What they deny is that each of these two selves is instantiated in a distinct valuation system in the brain. The evidence we have thus far, Glimcher argues, points in the direction of the existence of just one valuation system in the brain.

Summing up, BES seems to believe that there is neuroscientific evidence supporting the view that two selves, who are supposed to value short-term gains and losses and long-term ones very differently, house in our breasts (or heads) also at the brain level. Glimcher and colleagues deny this. They argue that the available neuroscientific evidence rather suggests that there is only one valuation system in the brain.

\section{Glimcher's project restated}

The foregoing discussion suggests how Glimcher's project is to be understood. First appearances notwithstanding, Glimcher's ultimate aim is not to vindicate standard economic theory, either at the level of individual behavior or at the level of neural activity (or both). As Glimcher (2010) makes clear, his ultimate aim is rather to develop an economic theory that is empirically more adequate than standard 
economic theory. Glimcher believes that the predictive power of standard economic theory leaves something wanting and that neuroscience can contribute to the development of a new economic theory with greater predictive power.

How then should we understand Glimcher et al.'s (2005) remark that studies such as Platt and Glimcher (1999) and Dorris and Glimcher (2004) show that desirabilities of all available courses of action are first literally computed in the brain and that subsequently the action is executed with the greatest desirability? Doesn't this amount to a vindication of expected utility theory? This is how proponents of BES conceive of these "surprising findings": as evidence supporting expected utility theory. But this is not how Glimcher (2010) conceives of them. Glimcher (2010) rather takes them as evidence supporting the view that there are spatially localizable areas in the brain where the last two stages of decision-making in the brain occur. What the "surprising findings" suggest, Glimcher (2010) now tells us, is that in the final stages of decision-making in the brain something similar occurs to what we would expect on a literal reading of expected utility theory: first, something like expected utilities ("desirabilities") are computed for all options, and second, the one with the highest expected utility is chosen. This should not be confused with the claim that the brain invariably produces the kind of behavior that is predicted by expected utility theory. Glimcher does not endorse this latter claim.

Some further explanations might be in order here. In the studies that produced the surprising findings, Platt and Glimcher (1999) and Dorris and Glimcher (2004), Glimcher was looking for a confirmation of his hypothesis that there are particular brain areas such as area LIP in which neurons encode something similar to expected utilities. This was indeed what he found. When Platt and Glimcher (1999) varied rewards and probabilities of rewards, for example, not only behavior (in this case, eye movements of monkeys) changed as predicted by expected utility theory, also neural activity in area LIP changed accordingly. In other words, what they found was that changes in individual choice behavior and changes in neural activity in LIP are linearly correlated. This strengthened Glimcher's belief that neural activity in areas such as LIP encodes "all things considered" expected personal values and that these values are predictive of individual behavior. Glimcher (2010) puts forward the hypothesis that valuation occurring in areas such as area LIP is the penultimate stage in all decision-making processes in the brain, only to be followed by the ultimate stage of choice, before motor circuits are activated and overt behavior is produced.

Glimcher (2010) suggests that what he calls "Hard-EU" should replace "SoftEU". "Soft-EU" refers to the prevailing revealed preference rendering of expected utility theory (Samuelson 1938; Houthakker 1950). On this rendering, expected utilities are inferred from observable individual choice behavior by the theorist. As Friedman and Savage (1948) famously put it, individuals behave as if they first compute the expected utilities of all available courses of action after which they choose (in an "arg max" operation) the one with highest expected utility. On the revealed preference rendering of expected utility theory, the theory is agnostic about whether or not individuals have the expected utilities ascribed to them on their minds and about whether or not they act on them. This is the crucial difference with Hard-EU: Hard-EU posits that individuals behave the way they do because expected 
personal values are computed in certain brain areas and choices are made on the basis of those in other brain areas. Unlike Soft-EU, Hard-EU is a causal theory. Whereas Soft-EU is silent on how decisions are made, Hard-EU tells us how decision-making proceeds in the brain.

Glimcher (2010) argues that shifting from Soft-EU to Hard-EU is an indispensable step in the project of neuroeconomics as he envisions it. The step involves what Glimcher himself calls a partial reduction of the logical objects of economic theory (such as expected utilities and choice) to neural correlates in the brain. Glimcher also makes clear, however, that this is only the first step in the project to be followed by an equally necessary second step. As Glimcher puts it succinctly, "we begin the neuroeconomic process of theory development with Hard-EU not because expected utility theory is right, but because for a synthetic neuroeconomist, Hard-EU is the right place to start." (ibid., 139) Hard-EU is put forward by Glimcher not as an attempt to vindicate expected utility theory, but rather as an attempt to make an informed connection between economic theory and neuroscience. Once the neural correlates are identified, we can bring what we know about neural activity in the relevant brain areas to bear on economic theory. Insights and findings from neuroscience are supposed to function here as mechanistic constraints on further economic theorizing. Thus, while we move from economic theory to neuroscience in the first step, we traverse in reverse direction in the second step: from neuroscience to economic theory.

Although it is too early to tell what the consequences will be of imposing the mechanistic constraints stemming from neuroscience on further economic theorizing, Glimcher leaves no doubt that substantive revisions of expected utility theory will be necessary. Expected utility theory cannot possibly be sustained, either as Soft-EU or as Hard-EU. Glimcher gives several reasons to believe that expected utility theory is inconsistent with our knowledge of neural activity in the relevant brain areas. Glimcher argues that we know that the firing rates of neurons encode relative, not absolute values, for example. We also know that neural activity is inherently stochastic. This explains why people exhibit indeterministic behavior when they are confronted with a series of lotteries in which the prizes change gradually. It suggests that deterministic utility models have to give way to random utility models, as first developed by McFadden (2005) and Gul and Pesendorfer (2006). We must replace Hard-EU by Hard-REU, Glimcher argues. Furthermore, we also know that the winner-take-all mechanism (which is supposed to be the neural counterpart of the "arg max" operation suggested by expected utility theory) does not provide the only way in which choice occurs in the brain. Sometimes choice is determined in a more direct way, as when some activity is produced when the firing rates of corresponding neurons exceed some critical threshold value. Glimcher notes that this is reminiscent of Herbert Simon's ideas about satisfying. Glimcher wants such knowledge to find its way into economic theory. Glimcher suggests that in the end, there will be a need to develop a behavioral neuroeconomics.

Thus Glimcher wants to forge an inter-theoretical bridge between economic theory and neuroscience not to vindicate standard economic theory, but to examine what revisions of it are necessary to better align it with neuroscience. It is also clear 
that Glimcher does not want to reduce economic theory to neuroscience. Presumably many economists are put off by neuroeconomics because they believe it entails the prospect of economics being reduced to neuroscience. If neuroscience can teach us everything we want to know about individual decision-making, then they might fear that economics becomes superfluous as a separate discipline (or as a "special science"; Fodor 1974). Fear of reductionism would be totally misplaced in Glimcher's case. It is not just that Glimcher argues that a complete reduction of economic theory to neuroscience would not even be possible in principle. The existence of emergent properties at the higher level of social phenomena that economic theory addresses defies any such attempt at complete reduction. Glimcher also explains that, if possible, he wants to keep several things in standard economic theory intact. Glimcher does not believe that the way to go forward in further developing economic theory is to abandon the utility-based approach, as proponents of a heuristics-approach seem to advocate. Glimcher is not trying to replace "utility" in economic theory by some other objects based in neuroscience (such as the action potential or firing rates of neurons). He is also not in favor of incorporating new parameters in utility models, as prospect theory aims to do. What we rather need is a revised set of axioms, where the revisions needed are guided by constraints stemming from psychology and neuroscience. Glimcher does not want to abandon the axiomatic approach in economics, primarily for the reason that the axiomatic approach allows for unambiguous empirical testing of the theory. He sees the joint work he has been doing lately with economists such as Caplin and Dean (Caplin et al. 2010), following Caplin and Dean's (2008) pioneering work, as a first step in that direction.

\section{The two camps gradually converging}

It now transpires that Glimcher's project of a synthetic neuroeconomics does not differ as markedly from that of BES as it seemed at first. Like BES, Glimcher is ultimately interested in developing new economic theories and models with greater predictive power than standard economic theory. Both "camps" agree that standard economic theory's predictive power is poor. They furthermore both believe that we can learn from current neuroscience what sorts of revisions of standard economic theory are needed to arrive at new economic theories with greater predictive power. And, at a more substantive level, it seems that proponents of BES have lately been convinced by Glimcher that there are not two valuation systems in the brain, but just one.

We saw above that Kable and Glimcher (2007) report that their findings strongly suggest that there is one common valuation system and that the values that guide behavior are computed in the vmPFC-striatal network. This is confirmed in Hare, Camerer and Rangel (2009)'s findings. Hare et al. (2009) note that this runs counter to the findings reported in McClure et al. $(2004,2007)$ that there are two separate valuation systems in the brain, one in the vmPFC associated with impulsive myopic decision-making when immediate rewards are available, and another one in the DLPFC associated with a more patient, self-controlled sort of decision-making that 
also takes account of delayed rewards. At the same time, however, Hare et al. (2009) also find some evidence in favor of McClure et al.'s view that the DLPFC does play a critical role in the deployment of self-control. Taken together, the view that emerges is one according to which “... the DLPFC influences self-control by modulating the value signal encoded in the vmPFC" (Hare et al. 2009, 648).

Glimcher (2010) agrees with Hare et al. (2009) that the DLPFC seems to be implicated in heeding long-term interests. Glimcher adds to this that it is probably the OFC that is specialized for the representation of immediately consumable rewards. Like the DLPFC, the OFC also provides inputs to the vmPFC (Glimcher 2010, 367). So it seems we witness a growing convergence between the two camps also with respect to this substantive issue. As proponents of BES, Hare et al. (2009) seem to agree with Glimcher that there is just one valuation system in the brain involved in intertemporal choice and that the vmPFC plays a crucial role in this system. And Glimcher seems to agree with Hare et al. that the vmPFC receives inputs from various brain areas, among them the DLPFC, for the processing of delayed rewards, and the OFC, for the processing of immediate rewards. The key to understanding the emerging communis opinio is to think in terms of upstream and downstream phases in the total causal chain of decision-making in the brain. Glimcher's hypothesis that there is one final common path in the brain through which all decisions are made relates to the alleged ulterior downstream phase, just before the motor circuits are activated, now seems to be accepted also by BES. Conversely, Glimcher seems to accept BES's hypothesis that further upstream we find the workings of several brain areas and circuits producing outputs that feed, as inputs, into the final common path. Neural activity in the DLPFC and the OFC occur in these earlier stages of decision-making in the brain.

It seems that how the outputs of the various brain areas combine to form inputs to the vmPFC is still poorly understood in neuroscience. This raises the issue of how much economists can rely on the present corpus of neuroscientific thought if they are searching for guidance as to how to revise standard economic theory. Glimcher admits that there are many things in the brain that we do not fully understand. Why then should economists take neuroscience as their lead in revising economic theory, as both BES and Glimcher recommend? Glimcher might retort that it does not matter much that the early upstream stages of decision-making in the brain are still dimly understood. If whatever happens at these early stages eventually always comes together in the common final stages, as he claims, then we would only need a solid understanding of neural activity in the areas that are relevant for the execution of these last two stages. And it seems we already understand the latter fairly well. Glimcher does not conceal, however, that as things presently stand, his claim that all decision-making in the brain terminates in two last stages that occur in particular brain areas, is speculative and contested within neuroscience (Glimcher 2010, 268). So the question remains whether in their attempts to develop an empirically more adequate economic theory, economists should put their cards on neuroscience.

Arguing, as I just did, that there is a growing consensus between the two camps of neuroeconomics, does not imply, of course, that all the initial disagreement between them disappeared. Behavioral economists seem to be more willing than Glimcher to abandon an axiomatic utility-based approach in economic theorizing. 
They might be comfortable with small incremental changes only in the short run. Most of the behavioral economists seem to be convinced that in the longer run, economic theory should open up to non-standard variables. Camerer (2007), for example, foresees that the largest payoff from neuroeconomics will come from replacing the utility-maximizing framework and its primitives such as preferences and choice by psychological and biological variables such as oxytocin (Zak et al. 2005; Kosfeld et al. 2005). This does seem to point in the direction of a reduction of economic theory to psychology and neuroscience; a prospect that ironically enough horrifies the neurobiologist Glimcher.

\section{Is an improved choice theory what economics needs most badly?}

Another point of agreement between the two camps seems to be the belief that an improved choice (or decision) theory is what economics needs most. Indeed, one sometimes gets the impression that both BES and Glimcher believe that individual choice behavior is all economic theory is about.

Glimcher (2010, 4-5) discusses the following example at the beginning of his book to give the reader a feel of the differences in outlook and perspective between an economist, a psychologist, and a neuroscientist. ${ }^{3} \mathrm{~A}$ man and a woman, both having serious, valuable and strictly monogamous sexual relationships at home, encounter each other for the first time at a conference. They start talking to each other, become more animated in their discussions as time passes and develop a strong mutual physical attraction. Were we to interview them at this point, they would both say that they would regret it if they slept with each other. Yet, they do spend the night together. If we were to interview them 2 weeks later, they would both say that sleeping together was a terrible mistake. This is an outcome they both clearly foresaw before they had sexual intercourse. So why did they nevertheless do it? Why did these two people choose to sleep together?

Glimcher argues that an economist answers this question by asserting that, all their talk about regret and mistake notwithstanding, the fact that the man and woman slept together reveals that they both preferred having the sexual experience. The main point Glimcher wants to drive home is that there is no place in the economist's outlook to accommodate the feeling of the man and woman after their sexual intercourse that they made a mistake. For an economist, by sleeping with each other the man and woman reveal that they preferred (1) a sexual experience in the near term and a small later risk of discovery that may cost them their permanent relationships over (2) no sexual experience in the near term and no risk of losing their permanent relationships. Only if they meet again next year at the same conference under identical circumstances, and decide not to have sex again, an economist might reconsider his first analysis that they both really preferred (1) over (2) at the first conference. With hindsight, the economist might then be willing to conclude that the man and woman preferred (2) over (1) at the first conference but

\footnotetext{
${ }^{3}$ Since there is no reason for me to discuss the typical outlook of a psychologist and neuroscientist here, I will only discuss what Glimcher takes to be the typical outlook of the economist.
} 
fell prey to a momentary lapse of reason. But the working hypothesis of an economist is that no matter what people say about their behavior or how they feel afterward, their preferences can be inferred from their observable behavior.

Another related working hypothesis is that preferences do not change over time, or at least not during the time span that economists address. The colloquial expression is that preferences are given. Glimcher implicitly refers to this additional working hypothesis when he argues that the economists may want to make predictions about future sexual encounters by these subjects (ibid., 15). Thus, an economist might predict that under identical situations the man and woman will succumb to the temptation to have sex again, no matter whether they say that they regretted that they did so earlier.

Glimcher seems to take for granted here that economists are interested in making these kinds of predictions. He assumes that the sort of future behavior economists would want to predict is individual behavior, the behavior of particular (types of) individuals, under identical circumstances. I think this is not what economists are ultimately interested in. What economists rather typically want to predict is aggregate ("social") behavior under changed circumstances. The assumption of fixed (or stable) preferences enables them to do exactly that: to predict how aggregate behavior responds to changes in circumstances. Thus, they are interested in questions such as: what if the visibility of extramarital sexual encounters (and hence the chance of discovery of adultery) is greater than it was at the first conference? Will there be less extramarital sexual intercourse in general? Economists are not terribly interested in individual behavior, let alone in the possibly idiosyncratic things that go into the decision-making process of a particular individual. Assumptions about individual decision-making are rather building blocks for theories about aggregate behavior.

This raises the worry that Glimcher's project, and for that matter also the project of BES, which aims at an improved understanding of individual choice, does not speak directly to the sorts of phenomena economists are ultimately interested in. A similar worry is voiced by Bernheim (2008a, 2009). Bernheim is not unsympathetic to the project of neuroeconomics, but confronts neuroeconomists with what in the meantime goes under the name of Bernheim's challenge (cf. Sobel 2009, Rustichini 2009 and Gul and Pesendorfer 2009):

Provide an example of a novel economic model derived originally from neuroeconomic research that improves our measurement of the causal relationship between a standard exogenous environmental condition-one with which economists have been historically concerned-and a standard economic choice. (Bernheim 2008a, 33; 2009, 122-123; Italics in the original).

For economists, prices and income are paradigm cases of standard exogenous conditions. And a paradigm case of a standard economic choice is consumers buying some commodity. To be more precise, it is not the individual demand of some particular consumer that economists are interested in, but aggregate market demand.

Camerer et al. (2005) and Sanfey et al. (2006) argue that the opening up of the black box of the mind by neuroscience is similar to the opening up of the black box of the firm in the new theory of the firm. They assume that economists are (or 
perhaps should be) as interested in the former as they have been in the latter. Bernheim disagrees. He argues that questions pertaining to the internal working of the firm fall squarely within the historical boundaries of mainstream economics, because they concern organized exchange between individuals. How different institutions such as the market or the firm affect resource allocation is arguably a, if not the general question that economists are historically preoccupied with. This is different for the opening of the black box of the mind, which clearly does not involve organized exchange between individuals and resource allocation among individuals. Neuroeconomics can only show its potential for economics, Bernheim seems to argue, if it leads to an improved understanding and prediction of how aggregate behavior responds to changes in incentives.

Who is Bernheim (and who are Gul and Pesendorfer (2008) and who am I, for that matter) to tell economists that they should not develop an interest in nonstandard choice, or in decision-making processes or in analyzing neural activity in the brain, it could be objected at this juncture? Isn't Camerer (2008) right that this amounts to imposing a "fundamentalist definition" of economics? Why not let other economists judge for themselves? After all, economists are (in) famous for their imperialist leanings. There is by now an economics of marriage, of politics, of criminal behavior, and of animal behavior. Why could there not be also an economics of neural activity? If you think this is a farfetched possibility, read Ross (2005). Ross argues that there are good reasons to believe that individual neurons (or groups of neurons) are more likely to qualify as rational economic agents (as defined in the prevailing revealed preference interpretation of expected utility theory) than individual persons.

Still, I think Bernheim addresses a legitimate sentiment that is prevalent in the economics profession: detailed "nitty-gritty" knowledge of how the brain works is very remote from the sorts of social patterns that most economists are interested in. If neuroeconomics wants to show its relevance for economics, it is well advised to respect this. This also relates to the issue of the very raison d'etre of economics as a special science. If economics did not have its own level of analysis, and were not interested in mechanisms, generalizations, counterfactuals at this level, why would there be a need for economics as a special science at all? Why not dispense with it altogether and rest content with more foundational sciences, such as psychology? Bernheim's challenge cannot be dismissed lightheartedly by neuroscientists as merely a cri de coeur of a conservative who regrets all these new developments in his own discipline.

If economists are intrinsically and ultimately interested in improving their predictions of how aggregate behavior responds to changes in incentives, is the sort of neuroeconomics that Glimcher and BES promote the best or right way to move forward? Perhaps there are other, more direct and better ways than looking at neuroscience to meet this interest. What BES and Glimcher's ENA seem to have in common are the beliefs, first, that enhancing our understanding of decision-making is the best way to improve economic theory and, second, that peering into the brain is the best way to enhance our understanding of decision-making. Starting with the latter, neuroeconomics has been characterized as embracing cognitive individualism (Wilcox 2008). The idea is that if we want to better understand the way we decide 
and behave, we should look inside the heads or skulls of individual persons. After all, isn't it obvious that decisions are made in our brains and not in our toes or hearts? BES and Glimcher's ENA both seem to believe that the extent to which individuals behave rationally is determined by neural activity in the brain areas that are involved in decision-making.

While all of this might be sensible and perhaps even obvious, it distracts attention away from the environment (or situation, circumstances, context) in which individuals are situated. To the extent that we behave more rationally now than we did a few decades or centuries ago, this might be due more to the success we had in creating our social and technological environment than with "intrinsic" changes in our brain. The fact that we tend to behave more rationally in anonymous marketsettings than in non-anonymous dyadic interactions (Smith 2007) might similarly be attributable to the success we had in creating institutional arrangements that aid our decision-making in the former settings. In cognitive science, the work of Hutchins (1995) on situated cognition and of Clark (1997) on institutional scaffolding come to mind here. Their message is that if we want to understand cognition, we should not look into the functioning of brains of individuals taken in isolation. We should rather look at them as parts of a larger whole and pay special attention to the prevailing social division of labor and also to the facilitating role of artifacts. Gigerenzer and Todd (1999) and Smith (2007) suggest we leave constructivist conceptions of rationality behind and replace those by "ecological rationality". Following Simon (1956), the emphasis is not only on the understanding of the various heuristics and decision rules that people deploy, but also and particularly on the environmental cues that trigger them. The idea is that each heuristic evolved in a particular context and that each heuristic has its own input conditions triggering them. We saw above that Glimcher fears that if we go this way, we have to posit the existence of a new heuristic for each choice anomaly we come across. Glimcher prefers to stick to the conventional axiomatic utility-based approach. But it is not at all clear whether this can be maintained in the face of the huge variability in contexts and in the behaviors that they entice. And if it can be maintained, the price we might have to pay for this is that we have to introduce a proliferation of nonstandard exogenous variables and an intractably complex utility-based model (Vromen 2010).

BES and Glimcher's ENA seem to believe that enhancing our understanding of decision-making is the best way to improve economic theory. But if it is aggregate rather than individual behavior that an improved economic theory should understand and predict better, we should perhaps look more at interaction patterns between individuals than at brain activity within individuals. The idea is reminiscent of what Bernheim calls the "organized interaction between individuals": the institutional mode of organization of interactions between individuals rather than activity within individuals takes center stage here. This necessitates moving away from the representative agent-type of modeling that long dominated economic theorizing (Kirman 1992). Rather than representative agent models, we should pursue models with interacting heterogeneous individuals. Although BES and Glimcher's ENA do not express a preference for either sort of modeling, the general properties of brain functioning that they describe are those of a representative agent. 
Models of interacting heterogeneous sorts of individuals, each type following its own simple decision rules, might serve our purposes better than representative agent models, even if the assignment of the simple decision rules to individuals is not based on a solid neuroscientific understanding of neural activity in brains.

It might be objected here that these various ways of making progress in economic theorizing are not mutually exclusive. Improving our understanding of the neural basis of decision-making might go hand in hand with making headway with models of interacting heterogeneous individuals, for example. And the one might also be conducive to the other. If we enhance our understanding of decision-making in the brain, for example, we might also come to understand better why and how we tend to behave more rationally in the one social context than in another. My main point here is not that there is no need for neuroeconomics if economic theory is ultimately interested in how aggregate behavior responds to changes in incentives. My main point is rather that what happens outside the skulls of individuals warrants at least as much attention as what happens inside their skulls. Investigating the way in which decisions are made in the brain should not blind us to, and should not prevent us from investigating the ways in which individuals respond to different sorts of environments and contexts and the ways in which they interact with each other.

\section{Conclusion}

Neuroeconomics started off as a hybrid project. Two camps could be clearly distinguished within neuroeconomics. One camp, BES, is looking for evidence in neuroscience and in brain data to undermine standard economic theory and to support behavioral models. BES sought to revise if not revolutionize economic theory on the basis of current neuroscience. At first sight, the other camp, Glimcher's ENA, sought to do exactly the opposite. It used standard economic theory to establish a paradigm shift in neuroscience. The two camps did not only differ markedly with respect to what sort of project neuroeconomics is, a project to improve economic theory or a project to improve neuroeconomic theory. They also differed with respect to substantive beliefs about how the brain functions. BES held that the two sorts of cognitive processes posited in dual-process theories are implemented in distinct interacting systems in the brain. Glimcher's ENA held that there is no evidence that there are two such systems operating in the brain.

Recent developments suggest that the gap between the two camps is closing, however. BES now seems to agree with Glimcher that there is just one valuation system operating in the final stages of decision-making in the brain. Conversely, Glimcher seems to agree with BES that the valuation system gets its inputs from several brain areas more upstream in the total causal chain that are implicated in various conflicting mental functions. The growing consensus between the two camps is not limited to substantive beliefs like these, it seems. It extends to what neuroscience ultimately aims at. Glimcher now seems to agree with BES that neuroeconomics wants to contribute to the development of a new economic theory with superior predictive power. Both hold that standard economic theory's predictive power is rather poor and that what we already know about neural activity in the 
relevant brain areas imposes useful constraints on the search for an empirically more adequate economic theory. This is not to say that BES and Glimcher's ENA now agree on everything. Whereas Glimcher wants to retain as much of the present axiomatic utility-based approach as possible, proponents of BES seem to believe that eventually abandoning that approach will be inevitable.

BES and Glimcher's ENA seem to converge on the view that the future of economic theory lies in an improved decision theory. While the potential importance of an improved decision theory for economic theory cannot be denied, however, it remains to be seen whether an improved decision theory is something economic theory needs most badly or most urgently. Especially if economic theory is not ultimately interested in individual decisions, but in how aggregate behavior responds to incentives, attention should not be limited to what happens inside the skulls of individuals. What happens outside the individuals' skulls, in the environments of individuals and in their interactions patterns, should also receive due attention.

Open Access This article is distributed under the terms of the Creative Commons Attribution Noncommercial License which permits any noncommercial use, distribution, and reproduction in any medium, provided the original author(s) and source are credited.

\section{References}

Bernheim BD (2008a, 2009) Neuroeconomics: a sober (but hopeful) appraisal, NBER Working Paper Series 13954

Brocas I, Carrillo JD (2008) The brain as a hierarchical organization. Am Econ Rev 98(4):1312-1346

Brocas I, Carrillo JD (2010) Neuroeconomic theory: using neuroscience to understand the bounds of rationality. www.voxeu.org/index.php?q=node/4758. Accessed April 2011

Camerer CF (2007) Neuroeconomics: using neuroscience to make economic predictions. Econ J 117(519):C26-C42

Camerer CF (2008) Neuroeconomics: opening the grey box. Neuron 60(3):416-419

Camerer CF, Loewenstein G (2004) Behavioral economics: past, present, and future. In: Loewenstein G, Rabin M, Camerer CF (eds) Advances in behavioral economics. Princeton University Press, Princeton

Camerer C, Loewenstein G, Prelec D (2005) Neuroeconomics: how neuroscience can inform economics. J Econ Lit 43(1):9-64

Caplin A, Dean M (2008) Dopamine, reward prediction error, and economics. Q J Econ 123:663-702

Caplin A, Dean M, Glimcher PW, Rutledge RB (2010) Measuring beliefs and rewards: a neuroeconomic approach. Q J Econ 125:923-960

Clark A (1997) Economic reason: the interplay of individual learning and external structure. In: Drobak J, Nye J (eds) The frontiers of the new institutional economics. Academic Press, San Diego, pp 269-290

De Quervain DJ, Fischbacher U, Treyer V, Schellhammer M, Schnyder U, Buck A, Fehr E (2004) The neural basis of altruistic punishment. Science 305(5688):1254-1258

Dorris MC, Glimcher PW (2004) Activity in posterior parietal cortex is correlated with the relative subjective desirability of action. Neuron 44(2):365-378

Evans JStBT (2010) Thinking twice: two minds in one brain. Oxford University Press, Oxford

Fodor JA (1974) Special sciences, or the disunity of science as a working hypothesis. Synthese 28(2):97-115

Friedman M, Savage LJ (1948) The utility analysis of choices involving risk. J Political Econ 56(4):279-304

Fudenberg D, Levine DK (2006) A dual-self model of impulse control. Am Econ Rev 96(5):1449-1476 Gigerenzer G, Todd PM (1999) Simple heuristics that make us smart. Oxford University Press, Oxford Glimcher PW (2003) Decisions, uncertainty and the brain: the science of neuroeconomics. MIT Press, Cambridge 
Glimcher PW (2010) Foundations of neuroeconomic analysis. Oxford University Press, Oxford

Glimcher PW, Dorris MC, Bayer HM (2005) Psychological utility theory and the neuroeconomics of choice. Games Econ Behav 52(2):213-256

Glimcher PM, Kable J, Louie K (2007) Neuroeconomic studies of impulsivity: now or just as soon as possible? Am Econ Rev 97(2):142-147

Glimcher PW, Camerer CF, Fehr E, Poldrack RA (2008) Neuroeconomics: decision making and the brain. Academic Press, London

Gul F, Pesendorfer W (2001) Temptation and self control. Econometrica 69(6):1403-1436

Gul F, Pesendorfer W (2006) Random expected utility. Econometrica 74:121-146

Gul F, Pesendorfer W (2008) The case for mindless economics. In: Caplin A, Schotter A (eds) The foundations of positive and normative economics. Oxford University Press, Oxford, pp 3-39

Gul F, Pesendorfer W (2009) A comment on Bernheim's appraisal of neuroeconomics. Am Econ J Microecon 1(2):42-47

Hare TA, Camerer CF, Rangel A (2009) Self-control in decision-making involves modulation of the vmPFC valuation system. Science 324(5927):646-648

Houthakker HS (1950) Revealed preference and the utility function. Economica 17:159-174

Hutchins E (1995) Cognition in the wild. MIT Press, Cambridge

Kable JW, Glimcher PW (2007) The neural correlates of subjective value during intertemporal choice. Nat Neurosci 10(12):1625-1633

Kahneman D (2003) A perspective on judgment and choice: mapping bounded rationality. Am Psychol 58(9):697-720

Kirman AP (1992) Whom or what does the representative individual represent? J Econ Perspect 6(2):117-136

Kosfeld M, Heinrichs M, Zak PJ, Fischbacher U, Fehr E (2005) Oxytocin increases trust in humans. Nature 435(7042):673-676

Laibson D (1997) Golden eggs and hyperbolic discounting. Q J Econ 112(2):443-477

McClure SM, Laibson DI, Loewenstein G, Cohen JD (2004) Separate neural systems value immediate and delayed monetary rewards. Science 306(5695):503-507

McClure SM, Ericson KM, Laibson DI, Loewenstein G, Cohen JD (2007) Time discounting for primary rewards. J Neurosci 27(21):5796-5804

McFadden D (2005) Revealed stochastic preference: a synthesis. Econ Theory 26:245-264

O’Donoghue T, Rabin M (1999) Doing it now or later. Am Econ Rev 89(1):103-124

Parker AJ, Newsome WT (1998) Sense and the single neuron: probing the physiology of perception. Annu Rev Neurosci 21(1):227-277

Platt ML, Glimcher PW (1999) Neural correlates of decision variables in parietal cortex. Nature 400(6741):233-238

Poldrack RA (2006) Can cognitive processes be inferred from neuroimaging data? Trends Cognit Sci 10(2):59-63

Ross D (2005) Economic theory and cognitive science: microexplanation. MIT Press, Cambridge, MA

Ross D (2008) Two styles of neuroeconomics. Econ Philos 24(3):473-484

Rustichini A (2009) Is there a method of neuroeconomics? Am Econ J Microecon 1(2):48-59

Samuelson PA (1938) A note on the pure theory of consumer's behavior. Economica 51(17):61-71

Sanfey AG, Rilling JK, Aronson JA, Nystrom LE, Cohen JD (2003) The neural basis of economic decision-making in the ultimatum game. Science 300(5626):1755-1758

Sanfey AG, Loewenstein G, McClure SM, Cohen JD (2006) Neuroeconomics: cross-currents in research on decision-making. Trends Cognit Sci 10(3):108-116

Schall JD, Thompson KG (1999) Neural selection and control of visually guided eye movements. Annu Rev Neurosci 22:241-259

Simon HA (1956) Rational choice and the structure of the environment. Psychol Rev 63(2):129-138

Smith VL (2007) Rationality in economics. Constructivist and ecological forms. Cambridge University Press, New York

Sobel J (2009) Neuroeconomics: a comment on Bernheim. Am Econ J Microecon 1(2):60-67

Vromen JJ (2007) Neuroeconomics as a natural extension of bioeconomics: the shifting scope of standard economic theory. J Bioecon 9(2):145-167

Vromen JJ (2010) Where economics and neuroscience might meet. J Econ Methodol 17(2):171-183

Wilcox N (2008) Against simplicity and cognitive individualism. Econ Philos 24(3):523-532

Zak PJ, Kurzban R, Matzner WT (2005) Oxytocin is associated with human trustworthiness. Horm Behav 48(5):522-527 